\title{
Placement and Sizing of Thyristor Controlled Series Compensator Using PSO Based Technique for Loss Minimization
}

\author{
Siti Amely Jumaat, Ismail Musirin, IEEE, Muhammad Murtadha Othman, IEEE, Hazlie Mokhlis, \\ IEEE
}

Abstract-Minimizing the transmission loss in power system is one of the important issues in power system research these days. Transmission loss can be reduced by installing reactive power compensation components. Installing the thyristor controlled series compensator (TCSC) in power system has been known to increase the voltage level in the system and hence reduce the system losses. This paper describes placement and sizing of FACTS devices based on Particle Swarm Optimization for minimization of transmission loss considering voltage profile and cost function. Particle Swarm Optimization (PSO) is one of the artificial intelligent search approaches which have the potential in solving such a problem. In this study one of FACTS device is used as a scheme for transmission loss. For this study, TCSC is chosen as the compensation device. Validation through the implementation on the IEEE 30-bus system indicated that PSO is feasible to achieve the task. The simulation results are compared with those obtained from the Evolutionary Programming (EP) technique in the attempt to highlight its merit.

Index Terms - FACTS devices, optimal sizing, Particle Swarm Optimization, transmission loss, minimization, static var compensator.

\section{INTRODUCTION}

The IEEE PES Task Force of the FACTS working Group defined for Flexible AC Transmission System (FACTS) as an alternating current transmission systems incorporating power electronic-based and other static controllers to enhance controllability and increase power transfer capability [1]. FACTS device is a concept proposed by N.G. Hingorani [2]; a well-known term for higher controllability in power system by means of power electronics devices. The Electric Power Research Institute were supporting the development of high power electronic for such applications as High Voltage DC

Siti Amely Jumaat is with the Faculty of Electrical and Electronics Engineering, Universiti Tun Hussein Onn Malaysia, 86400 Parit Raja, Batu Pahat, Johor, Malaysia (e-mail: sitiamely1979@gmail.com).

Ismail Musirin is with the Faculty of Electrical Engineering, Universiti Teknologi MARA, 40450 Shah Alam, Selangor, Malaysia (e-mail: ismailbm1@gmail.com).
(HVDC) transmission and reactive compensation of ac line, and in the late 1980s formalized the concept of FACTS [3]. The FACTS initiative was originally launched with main objectives to increase the power transfer capability of transmission system and to keep power flow over designed routes. The benefits of FACTS devices are increasing system transmission capacity, power flow, control flexibility and rapidity [4], to improve transmission system management, increased dynamic, transient grid stability and enabling environment [5]. FACTS devices provide strategic benefits for improved transmission system management through better utilization of existing transmission assets, increased transmission system reliability and availability, increased dynamic and transient grid and enabling environmental benefits [6].

In this paper, PSO technique is proposed to optimize the placement and sizing of FACTS devices in order to minimize the transmission loss and increase the voltage profile in the system. The TCSC is chosen as the device for compensation and modeled as a reactive source added at the line. The PSO and EP techniques performed on the IEEE 30-bus system have indicated that the proposed methods are worth in loss minimization scheme.

\section{THYRISTOR CONTROLLED SERIES COMPENSATOR (TCSC)}

Glexible AC Transmission Systems (FACTS) devices have Feveral types namely: thyristor controlled static compensator (TCSC), static var compensator (SVC), thyristor controlled phase shifter transformer (TCPST), unified power flow controller (UPFC) and static compensator (STATCOM) [11-12]. The model of a transmission line with series impedance $\left(z_{i j}=r_{i j}+j x_{i j}\right)$ and a TCSC connected between bus- $i$ and bus- $j$ is shown in Figure 1.a. and Figure 1.b. During the steady state the TCSC can be considered as a static reactance $j x_{c}$. By modifying the reactance of the transmission line, the TCSC acts as the inductive or capacitive compensation respectively. In this research, the reactance of the transmission line is adjusted by TCSC directly. The rating of TCSC depends on the reactance of the transmission line where the TCSC is located: 


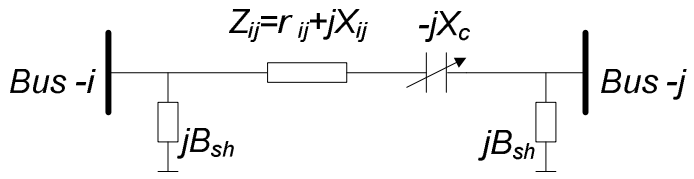

Fig. 1.a Model of TCSC

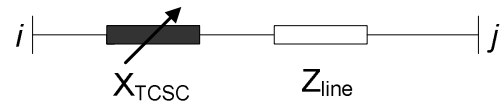

Fig. 1.b Block diagram of TCSC

$$
\begin{aligned}
& Z_{i j}=Z_{\text {line }}=r_{i j}+X_{i j} \\
& X_{i j}=X_{\text {line }}+X_{\text {TCSC }} \\
& X_{\text {TCSC }={ }_{\text {tcsc }}} \times X_{\text {line }}
\end{aligned}
$$

Where $X_{i j}$ is the total reactance of the transmission line, $X_{\text {line }}$ is reactance of the transmission line, $X_{\text {tcsc }}$ is reactance of TCSC, and $r_{t c s c}$ is the coefficient which represents the degree of compensations by TCSC. To avoid over compensation, the working range of the TCSC is chosen between $-0.8 X_{\text {line }}$ and $0.2 X_{\text {line }}[7,8,9,10]$.

\section{A. TCSC Cost Function}

The cost of installation of TCSC devices has been mathematically formulated and given by the following equation $[9,11]$ :

$$
I C=C_{\text {TCSC }} \times S \times 1000
$$

Where

$I C=$ the installation cost TCSC devices in [US\$],

$C_{T C S C}=$ the cost of TCSC devices in [US\$/KVar]

Installation of TCSC device can be calculated using the cost function given by $[9,11]$ :

$$
\begin{aligned}
& C_{\text {TCSC }}=0.0015 \mathrm{~S}^{2}-0.7130 \mathrm{~S}+153.7[\mathrm{US} \$ / \mathrm{KVar}] \\
& S=\mid Q_{2}-Q_{1}^{Q ।}
\end{aligned}
$$

where

$S$ = operating range of TCSC in [MVar]

$Q_{l}=$ reactive power flow through the branch before TCSC installation.

$Q_{2}=$ reactive power flow through the branch after TCSC installation.

\section{MODERn OptimizATION TECHNIQUES}

Optimization technique is an important approach in the aim to obtain the most suitable location and sizing of TCSC installation. In this study PSO is chosen due to its capability to achieve optimal solution.

\section{A. Particle Swarm Optimization (PSO)}

The Particle Swarm Optimization (PSO) algorithm originally is developed by Kennedy and Eberhart based on the social behaviors of animal swarms (e.g. bird blocks and fish schools) [12]. The PSO provides a population-based search procedure in which individuals called particles and changes their positions. The position of each particle is presented in $\mathrm{X}$ $\mathrm{Y}$ plane. Each particle moves to the new position using velocity according to its own experience called as $P_{\text {best }} . G_{b e s t}$ is the overall best value obtained so far by any particle in the population. By time to time, the PSO consists of velocity changes of each particle towards its $P_{\text {best }}$ and $G_{\text {best }}$ [13-14].

Each particle tries to modify its current position and velocity according to the distance between its current position and $P_{\text {best }}$, and the current position and $G_{\text {best }}$. After finding the best values the particle updates its velocity and position. Velocity of each particle can be modified by equation (6) [15 17].

$$
\begin{aligned}
v_{i}^{k+1}=w & \times v+c_{1} \times \text { rand }_{1} \times\left(P_{\text {best }_{i}}-s_{i}^{k}\right) \\
& +c_{2} \times \text { rand }_{2} \times\left(G_{\text {best }_{i}}-s_{i}^{k}\right)
\end{aligned}
$$

where

$$
\begin{aligned}
v_{i}^{k+1}= & \text { velocity of particle } t \text { at iterations } \\
w & =\text { weight function } \\
\mathrm{c}_{1} \text { and } \mathrm{c}_{2}= & \text { weight coefficient both equal to } 2 \\
\operatorname{rand}_{1} \text { and } \operatorname{rand}_{2}= & \text { random number between } 0 \text { and } 1 \\
\mathrm{~s}_{\mathrm{i}}^{\mathrm{k}}= & \text { current position of particle } i \text { at iteration } k \\
P_{\text {best }}= & \text { best position of particlei }- \text { th up to the } \\
& \text { current iteration } \\
G_{\text {best }}= & \text { best overall position found by the particle } \\
& \text { up to the current iteration. }
\end{aligned}
$$

Weight function is given by (7) [15 -18]:

$$
w=w_{\max }-\frac{w_{\text {max }}-w_{\text {min }}}{\text { iter }_{\text {max }}} \times \text { iter }
$$

where

$$
\begin{aligned}
w_{\text {max }} & =\text { maximum weight equal to } 0.9 \\
w_{\text {min }} & =\text { minimum weight equal to } 0.4 \\
\text { iter }_{\text {max }} & =\text { maximum iteration number, and } \\
\text { iter } \quad & =\text { current iteration number. }
\end{aligned}
$$

The new position can be modified (8) 


$$
s_{i}^{k+1}=s_{i}^{k}+v_{i}^{k+1}
$$

The general flowchart of PSO is shown in Fig. 2[19].

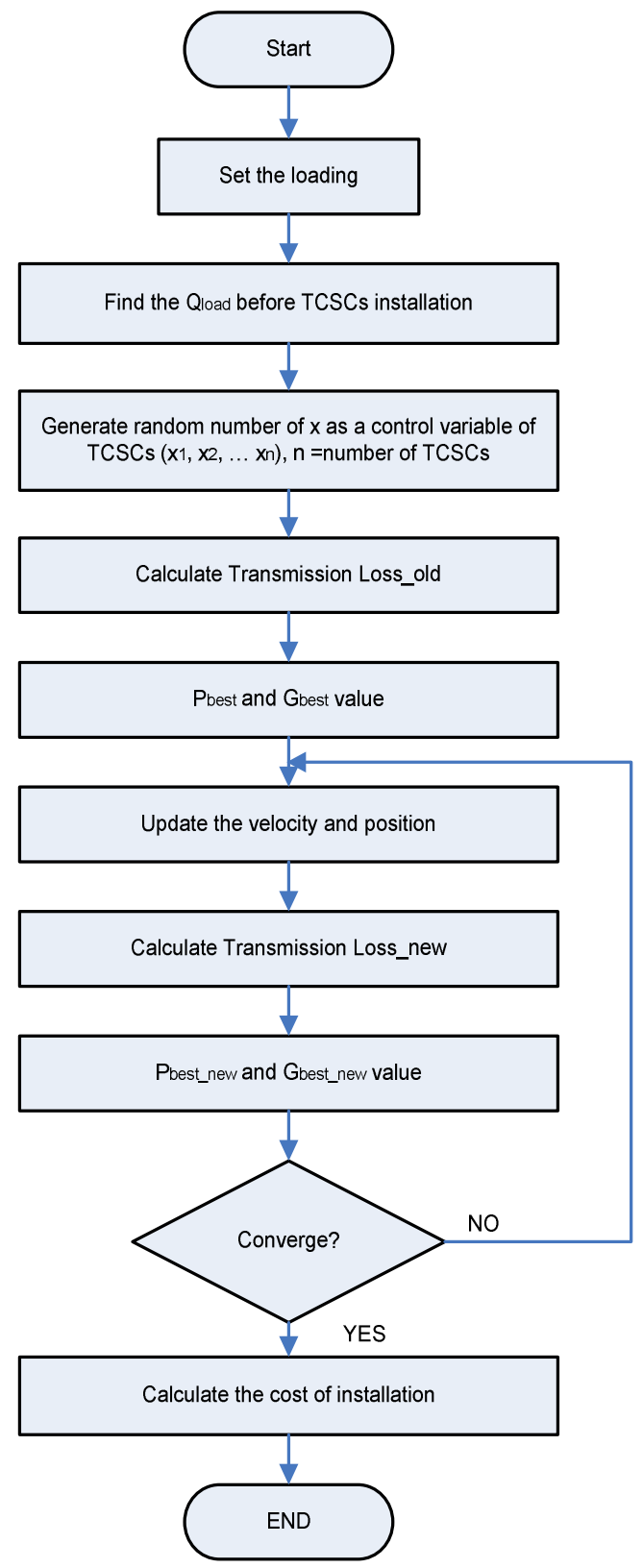

Fig. 2. Flowchart of Particle Swarm Optimization (PSO) algorithm for TCSC parameters.

\section{B. Evolutionary Programming (EP)}

The Evolutionary Programming (EP) is one of the artificial intelligent method which was introduced by David B. Fogel in 1960 [20]; inspired from natural selection process to find the global optimums of complex problem [21]. It is an evolutionary algorithm which based on computational models of fundamental evolutionary processes such as initialization, mutation, selection and reproduction. Fogel [21], proposed EP to define the optimal placement of FACTS device for maximization the total transfer capability (TTC) of power system. EP also searches for FACTS parameters, FACTS locations, and the real power generations except the slack bus in power system, the real power loads in sink area and generation bus voltages. The flowchart of EP is shown in Figure 3.

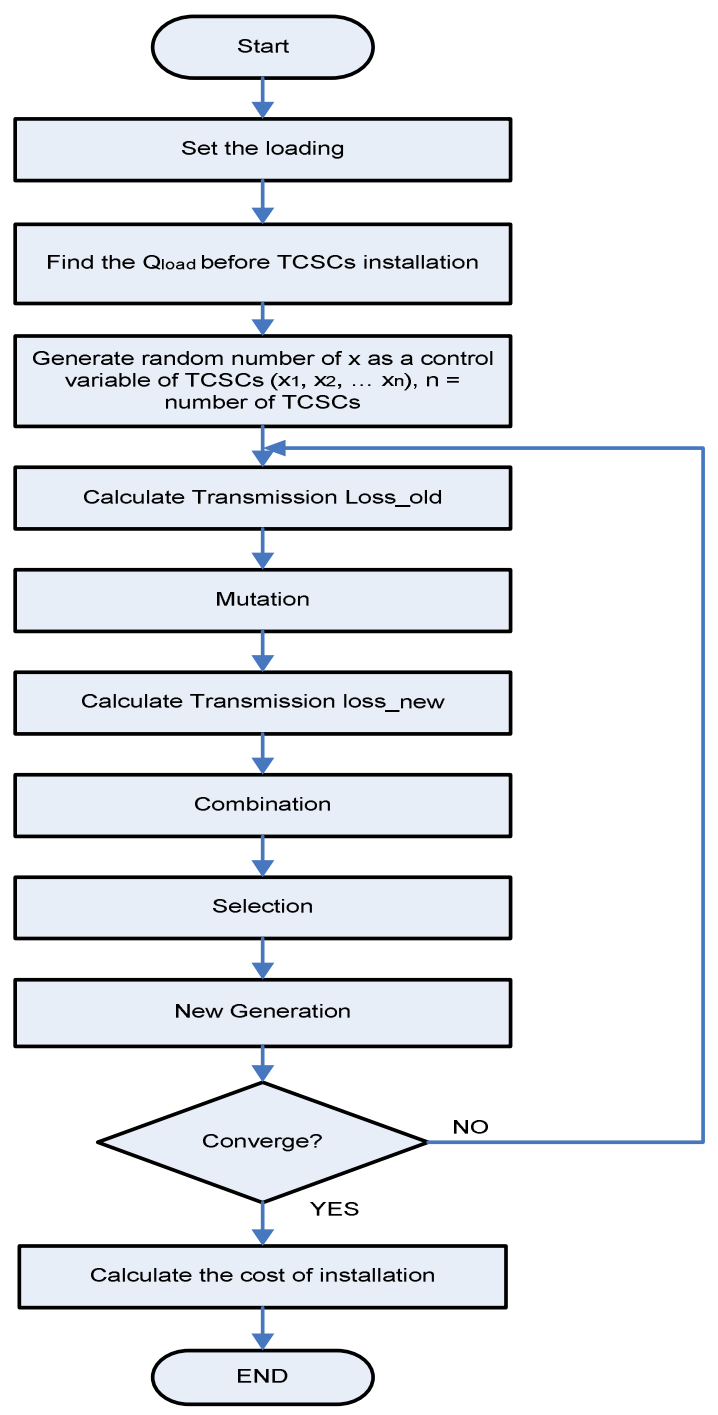

Fig. 3: Flowchart of Evolutionary Programming (EP) optimization algorithm for TCSC parameters.

\section{RESULTS AND DISCUSSION}

The IEEE 30-bus system has been used to demonstrate the application of the proposed formulation and evaluate the effectiveness of the PSO and EP in the solving the TCSC installation problem. Figure 4 shows the single line diagram of the test system. The system consists of 41-branches, 6 generator buses, and 22 load-buses. The linedata and the busdata of the IEEE 30 bus system are given in [5]. The parameters for the optimization process are listed in Table I. 
TABLE I PARAMETERS FOR OPTIMIZATIONS PROCESS

\begin{tabular}{c|c}
\hline Parameters & PSO \\
\hline Population Size & 20 \\
\hline Inertial Weight, $w$ & 0.4 and 0.9 \\
\hline Constant, $c_{1}$ & 3 \\
\hline Constant, $c_{2}$ & 3 \\
\hline Number of iteration & 100 \\
\hline Rand $_{1}$ & 0 to 1 \\
\hline Rand $_{2}$ & 0 to 1 \\
\hline
\end{tabular}

The TCSC installations in the transmission system to improve the transmission loss in the system have been conducted at several load conditions subjected to buses 26 and 29.

A. Transmission Loss, Voltage Profile and Cost of Installation at Bus 26

Results for transmission loss minimization when load at bus 26 are subjected to load variation are tabulated in Table II. Results for location and sizing of TCSC to achieve loss for this case can be referred to the same table. For instance, at loading condition is 30MVar the transmission loss has been reduced from $26.5184 \mathrm{MW}$ to $22.6478 \mathrm{MW}$ using the PSO technique. In order to achieve this, the location of TCSC, is line-34 and the sizing of TCSC, is -0.4584 p.u. Besides that, the transmission loss has been reduced to $23.8334 \mathrm{MW}$ when using the EP technique. The location for installation of TCSC is line-34 and the sizing is -0.2248 p.u. These are shown in Table III.

Figure 4 illustrates the results for voltage profile when load variation is subjected to bus 26 . From the results it is shown that TCSC installation manages to improve the voltage profile better until 0.9p.u - 1.00p.u. Figure 5 shows the cost of installation for TCSC when load variations are subjected to Bus 26. From the chart bar, it is observed that the cost of installation increased consequently as the reactive power loading in increased.

TABLE II

TRANSMISSION LOSS REDUCTION LOAD VARIATION AT BUS 26 USING PSO TECHNIQUE.

\begin{tabular}{c|c|c|c|c}
\hline \multirow{2}{*}{$\begin{array}{c}\text { Loading } \\
\begin{array}{c}\text { Condition } \\
\text { Qd26 } \\
\text { (MVar) }\end{array}\end{array}$} & without & $\begin{array}{c}\text { with } \\
\text { TCSC }\end{array}$ & $\begin{array}{c}\text { location } \\
\text { TCSC }\end{array}$ & $\begin{array}{c}\text { TCSC } \\
\text { sizing }\end{array}$ \\
\cline { 2 - 3 } 10 & 18.2785 & 18.0485 & 2 & -0.0277 \\
\hline 20 & 20.3393 & 19.8915 & 35 & -0.5474 \\
\hline 30 & 26.5184 & 22.6478 & 34 & -0.4584 \\
\hline
\end{tabular}

TABLE III

TRANSMISSION LOSS REDUCTION LOAD VARIATION AT BUS 26 USING EP TECHNIQUE

\begin{tabular}{|c|c|c|c|c|}
\hline \multirow{2}{*}{$\begin{array}{l}\text { Loading } \\
\text { Condition } \\
\mathrm{Q}_{\mathrm{d} 26} \\
\text { (MVar) } \\
\end{array}$} & \multicolumn{2}{|c|}{ Loss (MW) } & \multirow{2}{*}{$\begin{array}{l}\text { location } \\
\text { line }\end{array}$} & \multirow[b]{2}{*}{ TCSC sizing } \\
\hline & $\begin{array}{l}\text { without } \\
\text { TCSC }\end{array}$ & $\begin{array}{l}\text { with } \\
\text { TCSC }\end{array}$ & & \\
\hline 10 & 18.2785 & 18.1103 & 13 & -0.2219 \\
\hline 20 & 20.3393 & 19.8885 & 35 & -0.5710 \\
\hline 30 & 26.5184 & 23.8334 & 34 & -0.2248 \\
\hline
\end{tabular}

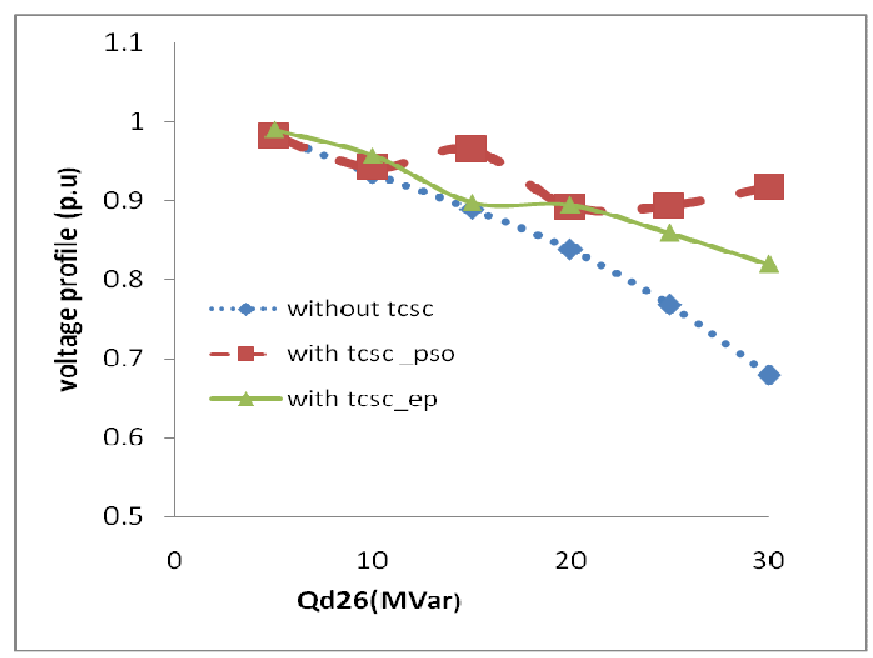

Fig. 4. Results for Voltage Profile When Load Variation at Bus 26

\section{B. Transmission Loss, Voltage Profile and Cost of Installation at Bus 29}

Results for transmission loss reduction when load buses 29 are subjected to load variation are tabulated in Table IV. The results for location and sizing of TCSC to achieve loss reduction at $22.7158 \mathrm{MW}$ to $20.6413 \mathrm{MW}$ using the PSO technique. In order to achieve this, the location of TCSC line36 and the sizing of TCSC is -0.3912p.u. Besides that, the transmission loss is reduced to $21.9260 \mathrm{MW}$ using the EP technique as shown in Table $\mathrm{V}$. The location for installation of TCSC is line-37 and the sizing is -0.3123 p.u. 


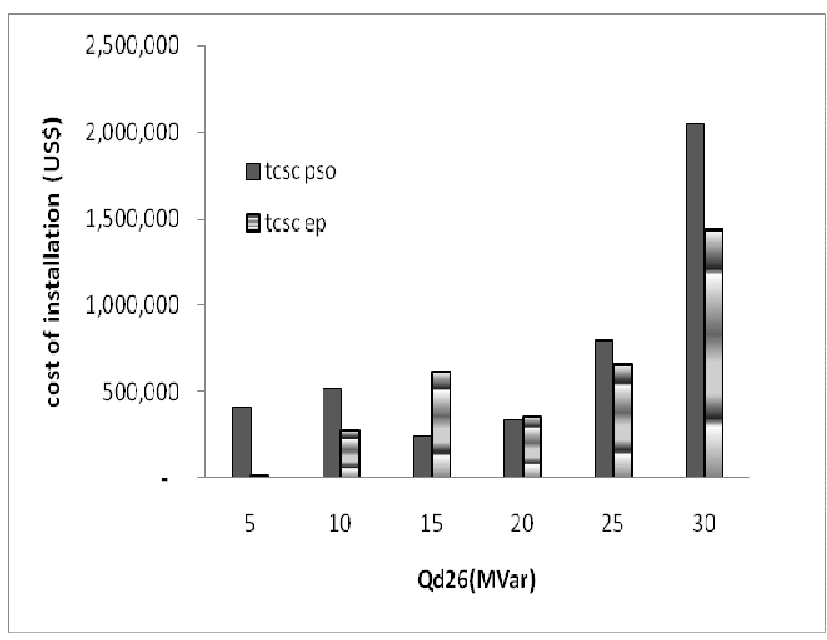

Fig. 5. Results of Cost Installation When Load Variation at Bus 26

Figure 6 shows the results of voltage profile when load variation is subjected to bus 29 . The same phenomena as that bus 26 can be observed in this case. The results shown that TCSC installation manage to improve the voltage profile better until 0.9p.u - 1.00p.u. Figure 7 shows the cost of installation for TCSC when load variations are subjected to bus 29. From the figure, it is observed that the cost of installation increased consequently as the reactive power loading in increased.

\section{CONCLUSION}

An approach for transmission loss minimization by using TCSC installation via PSO and EP as the optimization technique has been presented in this paper. Source code of PSO and EP optimization techniques were developed to determine the optimal location and sizing of TCSC in order to minimize the transmission loss in the system. Besides that, the voltage profiles and cost installation of TCSC resulted from the study could be taken as a reference for power system operators. Result shows that the implementations of PSO and EP have minimized the transmission loss and improved the voltage profile of the system indicating it as a feasible technique to perform the optimization process. For the future work, other FACTS device such as static compensator (STATCOM), thyristor controlled phase shifter transformer (TCPST), or unified power flow controller (UPFC) can be incorporated together to achieve similar task.

TABLE IV

TRANSMISSION LOSS REDUCTION LOAD VARIATION AT BUS 26 USING PSO TECHNIQUE.

\begin{tabular}{c|c|c|c|c}
\hline \multirow{2}{*}{$\begin{array}{c}\text { Loading } \\
\begin{array}{c}\text { Condition } \\
\text { Qd29 } \\
\text { (MVar) }\end{array}\end{array}$} & without & with TCSC & location & \multirow{2}{*}{$\begin{array}{c}\text { line } \\
\text { TCSC } \\
\text { sizing }\end{array}$} \\
\hline 10 & 18.1682 & 17.9937 & 13 & -0.1835 \\
\hline 20 & 19.4699 & 19.0105 & 36 & -0.3445 \\
\hline 30 & 22.7158 & 20.6413 & 36 & -0.3912 \\
\hline
\end{tabular}

TABLE V

TRANSMISSION LOSS REDUCTION LOAD VARIATION AT BUS 26 USING EP TECHNIQUE.

\begin{tabular}{c|c|c|c|c}
\hline \multirow{2}{*}{$\begin{array}{c}\text { Loading } \\
\begin{array}{c}\text { Condition } \\
\text { Q } \\
\text { (MVar) }\end{array}\end{array}$} & \multicolumn{2}{|c|}{ Loss (MW) } & location & \\
\cline { 2 - 3 } & wCSC & $\begin{array}{c}\text { without } \\
\text { TCSC }\end{array}$ & $\begin{array}{c}\text { TCSC } \\
\text { sizing }\end{array}$ \\
\hline 10 & 18.1682 & 17.9944 & 13 & -0.1557 \\
\hline 20 & 19.4699 & 19.0111 & 36 & -0.3076 \\
\hline 30 & 22.7158 & 21.9260 & 37 & -0.3123 \\
\hline
\end{tabular}

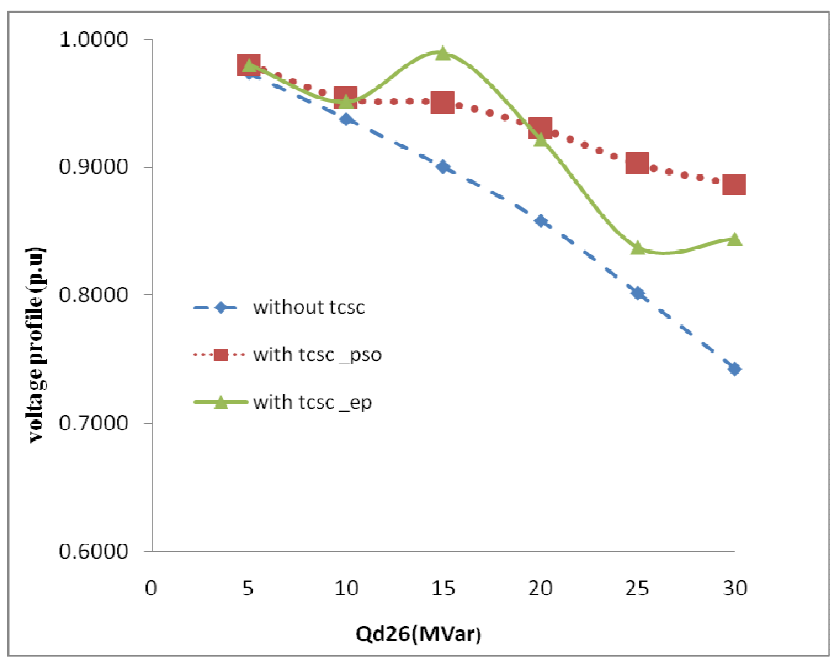

Fig. 6. Results for Voltage Profile When Load Variation at Bus 26

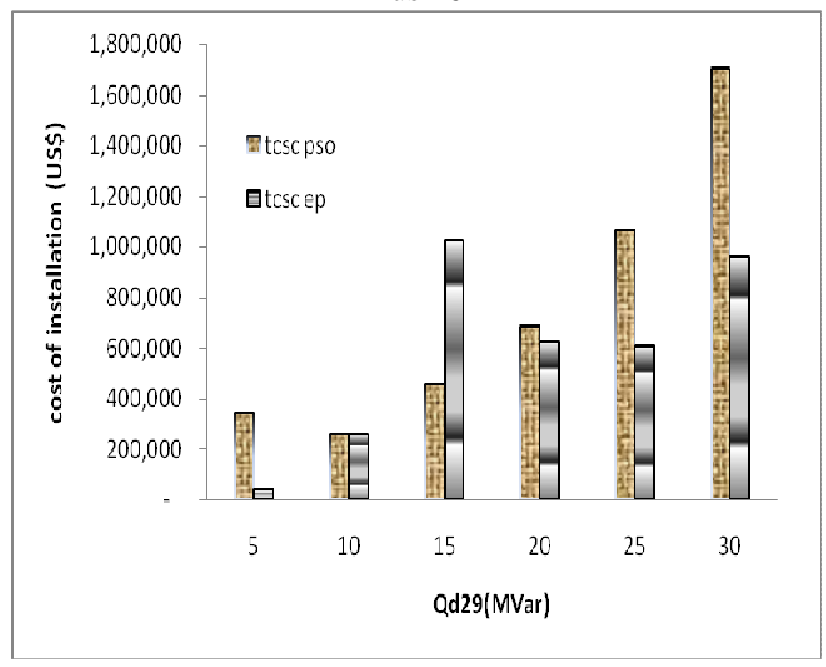

Fig. 7. Results of Cost Installation When Load Variation at Bus 29 


\section{REFERENCES}

[1] Narain G. Hingori, Laszlo Gyugy, "Understanding FACTS Concepts and Technology of Flexible AC Transmission Systems, IEEE Press, 2000.

[2] K. Y. Lee and F.F. Yang, "Optimal Reactive Power Planning using Evolutionary Algorithms: A Comparative Study for Evolutionary Programming, Evolutionary Strategy, Genetic Algorithm, and Linear Programming", IEEE Transactions on Power System, Vol. 13, No. 1, 1998, pp. 101-108.

[3] Y.H.Song, and A.T.John, "Flexible Transmission System (FACTS)", IEE Power and Energy Series 30, 1999.

[4] Saravanan. M, Slochanal. S.M.R, Venkatesh. P, Abraham, P.S, "Applications of PSO Technique for Optimal Location of FACTS Devices Considering System Loadability and Cost of Installation," in Proc $20057^{\text {th }}$ International Power Engineering Conference (IPEC). Pp.716 - 721 Vol. 22005

[5] Phashant Kumar Tiwari, and Tog Raj Sood, "Optimal Location of FACTS Devices in Power System Using Genetic Algorithm," in Proc. IEEE World Congress on Nature and Biologically Inspired Computing (NaBIC 2009), 2009.

[6] P. Pezzini, O.G. Bellmunt, and A. S. Andrue, "Optimization Techniques to improve energy efficiency in power system," International Journal Renewable and Sustainable Energy 2011, 2028-2041.

[7] S. Gerbex, R. Cherkaoui, and A. J.Germond, "Optimal location of multitype FACTS devices in a power system by means of genetic algorithms," IEEE Trans. Power System, vol. 16, pp 537-544, August. 2001.

[8] T.T.Lie and W. Deng, "Optimal flexible AC transmission systems (FACTS) devices installation," Electrical power \& Energy System, vol 19, No. 2 pp. 125-134, 1997.

[9] L.J. Cai, I.Erlich, and G.Stamtsis, "Optimal Choice and Allocation of FACTS Devices in Deregulated Electricity Market using Genetic Algorithm", in Proc. Power Systems Conference and Exposition 2004. (IEEE PES 2004) 2004 , pp. 201 - 207 vol.1 2004.

[10] Idris. R.M, Kharuddin. A, and Mustafa, M.W, "Optimal Choice of FACTS devices for ATC Enhancement Using Bees Algorithm," in Proc. 2009, Power Engineering Conference, 2009. (AUPEC 2009). Australasian Universities 2009, pp. 1 - 6, 2009.

[11] Phashant Kumar Tiwari, and Tog Raj Sood, "Optimal Location of FACTS Devices in Power System Using Genetic Algorithm," in Proc. IEEE World Congress on Nature and Biologically Inspired Computing (NaBIC 2009), 2009.

[12] J. Kennedy, and R. Eberhart, "Particle Swarm Optimization," in Proc. 1995 IEEE International Conf. on Neural Network, vol 4, pp. 19421948.

[13] Chansareewittaya. S, and Jirapong, P, "Power Transfer Capability Enhancement with Multitype FACTS Controllers Using Particle Swarm Optimization," in Proc. 2010 IEEE TENCON Conference_2010, pp 42 47E. 2010.

[14] Hashemzadeh. H, and Hosseini. S.H., "Locating Series FACTS Devices Using Line Outage Sensitivity Factors and Particle Swarms Optimization for Congestion Management," Power \& Energy Society General Meeting, 2009 (PES '09). pp 1-6, 2009.

[15] Saravanan. M, Slochanal. S.M.R, Venkatesh. P, Abraham, P.S, "Applications of PSO Technique for Optimal Location of FACTS Devices Considering System Loadability and Cost of Installation," in Proc $20057^{\text {th }}$ International Power Engineering Conference (IPEC). Pp. 716 - 721 Vol. 22005

[16] G.I.Rashed, H.I.Shaheen, S.J.Cheng, "Optimal Locations and Parameters Settings of Multiple TSCSs for Increasing Power System Loadability Based on GA and PSO techniques, in Proc 2007 Third IEEE International Conference on Natural Computation (ICNC 2007), 2007.

[17] Sundareswaran. K, Hariharan. B, Parasseri. F.P, Antony. D.S, and Subair, B, "Optimal Placement of Static Var Compensators (TCSC's) Using Particle Swarm Optimization," in Proc 2010, International Conference on Power, Control and Embedded Systems (ICPCES), 2010 2010 , pp. $1-4,2010$.

[18] S. Auchariyamet, and S.Sirismrannukul, "Optimal Reactive Power Planning with FACTS Devices by Particle Swarm Optimization", In
Proc. $8^{\text {th }}$ International conference on Advances in Power System Control, Operation and Management (APSCOM 2009), 2009, pp. 1 - 6. 2009.

[19] S. Chansareewittaya, and P, Jirapong, "Power Transfer Capability Enhancement with Multitype FACTS Controller Using Particle Swarm Optimization," in Proc IEEE TENCON 2010.

[20] G. Wei, "Comparison Study of Genetic Algorithm and Evolutionary Programming", Proc. of the Third International Conference on Machine Learning and Cybernetics, Vol. 1, No. 1, 2004, pp. 204-209.

[21] G. B. Fogel and D.B. Fogel, "Continuous Evolutionary Programming: Analysis and Experiments", An International Journal of Cybernetics and Systems, Vol. 26, 1995, pp. 79-90.

[22] Jumaat.S.A, Musirin. I, Murtadha. O.M., Mokhlis. H. "PSO Based Technique for Loss Minimization Considering Voltage Profile and Cost Function", in Proc. of the $5^{\text {th }}$ International Conference Power Engineering and Optimization (PEOCO), 2011, pp. 36 - 4.

[23] Jumaat. S.A., Musirin. I., Othman. M.M., Mokhlis. H. "Transmission Loss Minimization Using SVC Based on Particle Swarm Optimization", in Proc of the IEEE Symposium Industrial Electronics and Applications (ISIEA 2011), 2011. pp: 419 - 424.

[24] Jumaat. S.A., Musirin. I., Othman. M.M., Mokhlis. H. "Optimal Location and Sizing of SVC Using Particle Swarm Optimization Technique", in Proc of the $1^{\text {st }}$ International Conference Informatics and Computational Intelligence (ICI 2011), 2011 , pp: 312 - 317

\section{BIOGRAPHIES}

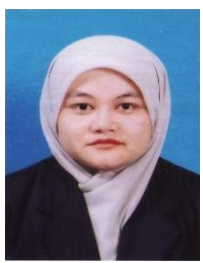

Siti Amely Jumaat was born in Johor, Malaysia on March 12, 1979. She graduated from the Institut Tun Hussein Onn (ITTHO-UTM) with honours degree in BSc. Electrical Eng. in 2001 and MEng. (Power), UTM in 2003. She is currently is pursuing a $\mathrm{PhD}$ in power system at Universiti Teknologi MARA, Malaysia. Her research interests include power system stability, facts devices and Artificial Intelligent techniques. She is also a member of BEM, IEM, IEEE, and IEEE Power Engineering Society (PES) 2008.

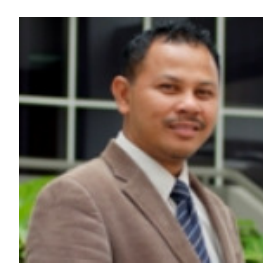

Associate Professor Dr. Ismail Musirin obtained Diploma of Electrical Power Engineering in 1987, Bachelor of Electrical Engineering (Hons) in 1990; both from Universiti Teknologi Malaysia, MSc in Pulsed Power Technology in 1992 from University of Strathclyde, United Kingdom and PhD in Electrical Engineering from Universiti Teknologi MARA, Malaysia in 2004. His research interest includes power system stability, optimization techniques, distributed generator and artificial intelligence. He is also a member of IEEE, IEEE Power Engineering Society and Artificial Immune System Society (ARTIST).

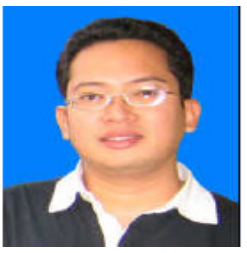

Dr. Muhammad Murtadha bin Othman received his B.Eng. (Hons) from Staffordshire University, England in 1998; M.Sc from Universiti Putra Malaysia in 2000 and $\mathrm{PhD}$ from Universiti Kebangsaan Malaysia in 2006. He currently lectures at the Universiti Teknologi MARA, Malaysia. His area of research interests are artificial intelligence, transfer capability assessment and reliability studies in a deregulated power system.

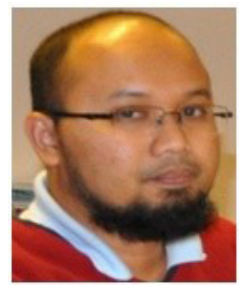

Hazlie Bin Mokhlis received his M.Sc. degree from Malaya University and PhD degree in 2009 from Manchester University, United Kingdom. His research interest is Electrical power system (Transmission and Distribution) Power quality, stability, EMC \& Islanding. 